\title{
MATHEMATICAL ANALYSIS OF A MODEL FOR THE DYNAMICS OF BROILER PRODUCTION IN NIGERIA
}

\author{
1,*'S.A. Egbetade, ${ }^{2}$ M.O. Ibrahim, and ${ }^{3}$ A. G. Farombi \\ ${ }^{1}$ Department of Mathematics \& Statistics, \\ The Polytechnic, Ibadan, Nigeria \\ ${ }^{2}$ Department of Mathematics, \\ University of Ilorin, Ilorin, Nigeria. \\ ${ }^{3}$ Department of Science Laboratory Technology, \\ Osun State Polytechnic, Iree, Nigeria. \\ "Corresponding Author Email: egbetades@yahoo.com
}

\begin{abstract}
In this paper, we propose a system of first order differential equations divided into four classes to describe broiler production in Nigeria. The model incorporates previous training, years of experience, capital and stocking capacity as major variables determining the dynamics of the physical phenomenon. The model equations are stated with underlying assumptions. Using basic mathematical techniques, positivity, boundedness, existence and uniqueness, of solution of the model are explored. The results showed that there exists a unique, positive and bounded solution of the model. This suggests the applicability of the model to study the determinants of broiler production in Nigeria and gives useful insights to assist economists and researchers in their empirical studies.
\end{abstract}

Keywords: broiler, mathematical model, positivity, boundedness, existence and uniqueness of solution

\section{Introduction}

In the Nigeria domestic poultry industry, the significance of broiler production cannot be overemphasized as it contributes a great turn over cycle and requires far less amount of capital (Aminu et al., 2010). In addition, it plays a very important role in protein supply in Nigeria (Omolayo, 2008). According to Food and Agriculture Organization (FAO), broiler has the most astounding protein content of $21-50 \%$, when compared with other animal protein obtained from cattle, goat and sheep (FAO, 2008) Beyond direct food production, poultry industry generally is a great contributor to Nigeria Gross Domestic Production (GDP), employment, poverty alleviation as well as income generation among the teeming population (Philip et al., 2009).

In order to meet the growing concerns of inadequate protein that Nigeria like most developing countries is confronted with, strategies that will encourage higher production is required. 
Surprisingly, mathematical modeling is central to solving many physical problems arising in the field of science, engineering and finance (Burges and Wood, 1980, Madubueze et al., 2017). As a solution to the problem, the role of mathematical models is inevitable. These models can be used to assess the critical impacts of capital, years of experience, previous training and stocking capacity as key parameters in determining broiler production and profitability of the business.

The present paper considers all these variables, proposes a model incorporating the parameters and performs mathematical analysis to suggest crucial data that should be collected to make general forecasts, estimations and predictions which would in turn assists policy makers and people involved in poultry enterprise.

\section{Mathematical Formulation}

We propose the following set of 1st order differential equations to describe the dynamics of broiler production in Nigeria.

$$
\begin{aligned}
& \frac{d P}{d t}=\gamma \alpha_{m}+\gamma \alpha_{s}-\alpha_{m} P-\alpha_{s} P \\
& \frac{d Q}{d t}=\gamma \Omega_{t}+\gamma \Omega_{u t}-\Omega_{t} Q-\Omega_{u t} Q \\
& \frac{d R}{d t}=\gamma \ell_{c}+\gamma \ell_{n}-\ell_{n} R-\ell_{c} R \\
& \frac{d W}{d t}=\gamma \theta_{l}+\gamma \theta_{h}-\theta_{h} W-\theta_{l} W
\end{aligned}
$$

With the initial conditions which are non-negative in the positive invariant region $\lambda$ such that $\left\{P_{0}, Q_{0}, R_{0}, W_{0}\right\} \in \lambda$

The descriptions of the variables and parameters of the model are given in Table 1. 


\begin{tabular}{|l|l|}
\hline Variable parameter & Description \\
\hline $\mathrm{P}$ & years of experience \\
\hline $\mathrm{R}$ & previous training \\
\hline $\mathrm{W}$ & capital \\
\hline$\gamma$ & stocking capacity \\
\hline$\alpha_{m}$ & growth rate \\
\hline$\alpha_{s}$ & many years of experience \\
\hline$\Omega_{t}$ & small years of experience \\
\hline$\Omega_{u t}$ & training rate \\
\hline$\ell_{c}$ & untrained \\
\hline$\ell_{n}$ & capital rate \\
\hline$\theta_{h}$ & no capital capacity rate \\
\hline$\theta_{l}$ & \\
\hline
\end{tabular}

\section{Table 1: Model Variables and Parameters}

\section{Mathematical Analysis}

\subsection{Positivity of Solution}

\section{Theorem 1}

Given that the initial conditions $\mathrm{P}_{0}, \mathrm{Q}_{0}, \mathrm{R}_{0}, \mathrm{~W}_{0}$ are non-negative and exist in the positive invariant region $\lambda$, then the solution set $\{P(t), Q(t), R(t), W(t)\}$ are all positive for all time $t \geq 0$. 
Proof

Consider equation (1)

$\frac{d P}{d t}=\gamma \alpha_{m}+\gamma \alpha_{s}-\alpha_{m} P-\alpha_{s} P$

which can be rewritten as

$\frac{d P}{d t} \geq-\left(\alpha_{m}+\alpha_{s}\right) P$

Integrating by separable variables and applying the initial conditions gives

$P(t) \geq P_{0} \ell^{-\left(\alpha_{m}+\alpha_{s}\right) t} \geq 0$

In a similar fashion, it can be shown that respective solution $\mathrm{Q}(\mathrm{t}), \mathrm{R}(\mathrm{t}), \mathrm{W}(\mathrm{t})$ of the model equations (3) - (4) remains positive in the invariant region $\lambda$. Hence, we conclude that the solution set $\{P(t), Q(t), R(t), W(t)\}$ of our model is positive in $\lambda$ for all $t \geq 0$.

\subsection{Existence and Uniqueness of Solution}

Consider the lVP

$$
\begin{aligned}
& x_{1}^{\prime}=f_{1}\left(t, x_{1}, \ldots, x_{n}\right), \quad x_{1}\left(t_{0}\right)=x_{10} \\
& x_{2}^{\prime}=f_{2}\left(t, x_{1}, x_{2}, \ldots x_{n}\right), x_{2}\left(t_{0}\right)=x_{20} \\
& \left.\begin{array}{ccc}
\cdot & \cdot & \cdot \\
\cdot & \cdot & \cdot \\
\dot{x}_{n}^{\prime}=f_{n}\left(t, x_{1}, x_{2}, \ldots, x_{n}\right), & \cdot & \cdot \\
x_{n}\left(t_{0}\right)= & \cdot & x_{n 0}
\end{array}\right\}
\end{aligned}
$$

We write the vectors 
$x=\left(\begin{array}{c}x_{1} \\ \cdot \\ \cdot \\ \cdot \\ x_{n}\end{array}\right)$

$f(t, x)=\left(\begin{array}{c}f_{1}\left(t, x_{1}, \ldots, x_{n}\right. \\ \cdot \\ \cdot \\ \cdot \\ f_{n}\left(t, x_{1}, x_{2}, \ldots, x_{n}\right.\end{array}\right)$

(9)

$x_{0}=\left(\begin{array}{c}x_{10} \\ x_{20} \\ \cdot \\ \cdot \\ \cdot \\ x_{n 0}\end{array}\right)$

Then, we may write equation (7) in the compact form

$x^{\prime}=f(t, x), x\left(t_{0}\right)=x_{0}$

Applying equation (11) to the model equations (1) - (4) results in the following differential equations

$f_{1}(t, x)=\gamma \alpha_{m}+\gamma \alpha_{s}-\alpha_{m} P-\alpha_{s} P$

$f_{2}(t, x)=\gamma \Omega_{t}+\gamma \Omega_{u t}-\Omega_{t} Q-\Omega_{u t} Q$

$f_{3}(t, x)=\gamma \ell_{c}+\gamma \ell_{n}-\ell_{n} R-\ell_{c} R$

$f_{4}(t, x)=\gamma \theta_{l}+\gamma \theta_{h}-\theta_{h} W-\theta_{l} W$ 
Then, we state the following theorem necessary for the proof of existence and uniqueness of solution of the model

Theorem 2

Let $\mathrm{V}$ denote a positive region such that $\left|t-t_{0}\right| \leq a,\left\|x-x_{0}\right\| \leq b$

Suppose that $\mathrm{f}(\mathrm{t}, \mathrm{x})$ satisfies the Lipschitz condition

$$
\left\|f\left(t, x_{1}\right)-f\left(t, x_{2}\right)\right\| \leq k\left\|x_{1}-x_{2}\right\|
$$

Whenever the pairs $\left(t, x_{1}\right)$ and $\left(t, x_{2}\right)$ belong to $V$ where $\mathrm{k}$ is a non-negative constant. Then there is a constant $\delta>0$ such that there exists a continuous unique vector solution $\mathrm{x}(\mathrm{t})$ of the system in equation (11) in the interval $\left|t-t_{0}\right| \leq \delta$

Remark: It is important to note that the condition (17) is satisfied by the requirement that $k=\frac{\partial f_{i}}{\partial x_{j}}, i=1,2, \ldots, n, j=1,2, \ldots, n$ continuous and bounded in V.

Now, if $f(t, x)$ defined by equation (12) - (15) has continuous partial derivatives on a bounded domain $\mathrm{R}$ such that

$1 \leq \in \leq R, \quad 0<R<\infty$

Then, $f(t, x)$ satisfies a Lipschitz condition in $\mathrm{R}$ and we have the following theorem 


\section{Theorem 3}

Let $\mathrm{V}$ denote the region defined in equation (16) such that equation (18) holds, then there exists a unique and bounded solution of the model system (1) - (4) in the region V.

Proof

By Theorem 2, it suffices to show that

$\left|\frac{\partial f_{i}}{\partial x_{j}}\right|, i, j=1,2,3,4$ are bounded

Now,

$\left|\frac{\partial f_{i}}{\partial x_{j}}\right|,=\left|-\alpha_{m}-\alpha_{s}\right|=\left|-\left(\alpha_{m}+\alpha_{s}\right)\right|<\infty$

$\left|\frac{\partial f_{i}}{\partial Q}\right|=\left|\frac{\partial f_{i}}{\partial R}\right|=\left|\frac{\partial f_{i}}{\partial W}\right|=0<\infty$

$\left|\frac{\partial f_{2}}{\partial Q}\right|=\left|-\Omega_{t}-\Omega_{u t}\right|=\left|-\left(\Omega_{t}-\Omega_{u t}\right)\right|<\infty$

$\left|\frac{\partial f_{2}}{\partial p}\right|=\left|\frac{\partial f_{2}}{\partial R}\right|=\left|\frac{\partial f_{2}}{\partial W}\right|=0<\infty$

$\left|\frac{\partial f_{3}}{\partial R}\right|=\left|-\ell_{n}-\ell_{c}\right|=\left|-\left(\ell_{n}+\ell_{c}\right)\right|<\infty$

$\left|\frac{\partial f_{3}}{\partial p}\right|=\left|\frac{\partial f_{3}}{\partial Q}\right|=\left|\frac{\partial f_{3}}{\partial W}\right|=0<\infty$ 


$$
\begin{aligned}
& \left|\frac{\partial f_{4}}{\partial W}\right|=\left|-\theta_{h}-\theta_{l}\right|=\left|-\left(\theta_{h}+\theta_{l}\right)\right|<\infty \\
& \left|\frac{\partial f_{4}}{\partial p}\right|=\left|\frac{\partial f_{4}}{\partial Q}\right|=\left|\frac{\partial f_{4}}{\partial W}\right|=0<\infty
\end{aligned}
$$

Clearly, equations (19) - (26) are bounded.

Hence, by Theorem 2 there exists a unique solution of equations (1) - (4) which satisfies equation (17). Theorem 3 is hereby established.

\section{Discussion of Results and Conclusion}

In this paper, we have analysed a model of broiler production. The solution set of the model was shown to be bounded, positive and unique. The importance of existence and uniqueness of solution is to identify the determinants of broiler production in Nigeria for significant improvement among broiler producers. Based on the findings of this paper, broiler production data on capital, previous training, years of experience and stocking capacity should be collected, fitted into the existing model, simulated over a period of time and make general assessments and forecasts on the potential impacts of the incorporated variables.

\section{References}

[1]. Aminu, A. Bello, M. B. Suleiman, A and Anegbe, M. J. (2010). Economic Analysis of Broiler Production in Kaduna Metropolis, Kaduna State. Journal of Social and Management Sciences 13(1), 93-100.

[2]. Omolayo, J. O. (2008), Economic Analysis of Broiler Production in Lagos State Poultry Estate, Nigeria. Journal of Investment and Management 7(1), 35-44.

[3.] FAO (2008). Food and Agricultural Organization. Poultry in the $21^{\text {st }}$ Century: Avian Influence and Beyond. Proceedings of the International Poultry Conference, Nov.5-7, 2007, Bangkok, Thailand.

[4.] Philip, D. Nkonya F. Pender, J. and Oni, O. (2009). Constraint to Increasing Agricultural Productivity in Nigeria. A review, Nigeria Strategy Support Program (NSSP). Background paper No. 6 
[5.] Burges, D. N. and Wood, A.D.(1980). Mathematical models in the Solid Management and Life Science. Elhs Horwood Limited, NewYork.

[6.] Blower, S. M. Mclean, A. R., Pircus, T. C. Small, P. M. Hopewell, P.C. Sanchez, M. A and Moss A. R. (1995). The Intrinsic transmission dynamics of tuberculosis epidemics. Nat. Med. 1(8), 815 -821

[7] Liao, S. J. and Chwang, A. T. (1998). Application of HAM in Non-linear Oscilations ASME, J. Appl. Mech.65, 914 -922.

[8.] Hethcote, H. W. (2000). The Mathematics of Infectious Diseases. SIAM Rev. 42(4) 599 -653.

[9.] Egbetade S. A. (2002). A Model of Macrophage and Tcell Infection by HIV M. Tech. Thesis, Ladoke Akintola University of Technology, Ogbomosho, Nigeria.

[10]. Egbetade, S. A., Oladipo Abodunwa, T. and Babalola, F. M. (2011). Global stability of endemic equilibrium state for a mathematical model of HIV/AIDS. Nig. J. of Science and Technology Res.4(1), 27-32.

[11.] Egbetade, S. A. (2017). Modeling of Tuberculosis (A Case Study of Oyo State of Nigeria) Ph.D Thesis, University of Ilorin, Ilorin, Nigeria.

[12.] Egbetade, S. A., Agboluaje, S, A and Olatunji, O. O. (2019). Qualitative Analysis of a SIR Model of Infectious Diseases. Science and Engineering Perspectives 14, 23 -27.

[13. ]Zhu, S. P. (2006). A closed from analytical solution for the evaluation of convertible bonds with constant dividend yield. Anzian Journal 47, 477- 494.

[14.] Okosun, K. O. and Makinde, D. O. (2013). Optimal control of Malaria in the presence of non linear incidence rate computational mathematics $12(1) 20-32$.

[15.] Madubueze, C. E. Kimber, A. R, Onah, E. S. and Abioyar T. (2017). Analysis of a Mathematical Model of Ebola Virus Disease with contact Tracing and Quarantine Measures. Transactions of Nigeria Association of Mathematical Physics 3, 75-82.

[16]. William, R. D.and Stanley, I. G. (1976). Elementary Differential Equation with Applications AddisonWesley Publishing Company, Inc. Phillipnes 1980, 1995. 